\title{
TU/e EmonONEN

\section{A reflection on Russell's ramified types and Kripke's hierarchy of truths}

Citation for published version (APA):

Kamareddine, F., \& Laan, T. D. L. (1995). A reflection on Russell's ramified types and Kripke's hierarchy of truths. (Computing science reports; Vol. 9518). Technische Universiteit Eindhoven.

Document status and date:

Published: 01/01/1995

\section{Document Version:}

Publisher's PDF, also known as Version of Record (includes final page, issue and volume numbers)

\section{Please check the document version of this publication:}

-A submitted manuscript is the version of the article upon submission and before peer-review. There can be important differences between the submitted version and the official published version of record. People interested in the research are advised to contact the author for the final version of the publication, or visit the $\mathrm{DOI}$ to the publisher's website.

- The final author version and the galley proof are versions of the publication after peer review.

- The final published version features the final layout of the paper including the volume, issue and page numbers.

Link to publication

\section{General rights}

Copyright and moral rights for the publications made accessible in the public portal are retained by the authors and/or other copyright owners and it is a condition of accessing publications that users recognise and abide by the legal requirements associated with these rights.

- Users may download and print one copy of any publication from the public portal for the purpose of private study or research.

- You may not further distribute the material or use it for any profit-making activity or commercial gain

- You may freely distribute the URL identifying the publication in the public portal.

If the publication is distributed under the terms of Article $25 \mathrm{fa}$ of the Dutch Copyright Act, indicated by the "Taverne" license above, please follow below link for the End User Agreement:

www.tue.nl/taverne

Take down policy

If you believe that this document breaches copyright please contact us at:

openaccess@tue.nl

providing details and we will investigate your claim. 
Eindhoven University of Technology

Department of Mathematics and Computing Science

A Reflection on Russell's Ramified Types and Kripke's Hierarchy of Truths

by

F. Kamareddine and T. Laan

$95 / 18$

ISSN 0926-4515

All rights reserved

editors: prof.dr. J.C.M. Baeten

prof.dr. M. Rem

Computing Science Report 95/18

Eindhoven, May 1995 


\title{
A Reflection on Russell's Ramified Types and Kripke's Hierarchy of Truths
}

\author{
Fairouz Kamareddine \\ Department of Computing Science \\ University of Glasgow \\ 17 Lilybank Gardens, GLasgow G12 8QQ, Scothand \\ e-mail fairouz@dcs.gla.ac.uk \\ Twan Laan* \\ Department of Mathematics and Computing Science \\ Eindhoven University of Technology \\ P.O.Box 513, 5600 MB Eindhoven, The Netherlands \\ e-mail laan@win.tue.nl
}

May 22, 1995

\begin{abstract}
Both in Kripke's Theory of Truth KTT [7] and Russell's Ramified Type Theory RTr [15, 8] we are confronted with some hierarchy. In RTT, we have a double hierarchy of orders and types. That is, the class of propositions is divided into different orders where a propositional function can only depend on objects of lower orders and types. Kripke on the other hand, has a ladder of languages where the truth of a proposition in language $L_{n}$ can only be made in $L_{m}$ where $m>n$. Kripke finds a fixed point for his hierarchy (something Russell does not attempt to do). We investigate in this paper the similarities of both hierarchies: At level $n$ of KTT the truth or falsehood of all order- $n$-propositions of RTT can be established. Moreover, there are order- $n$-propositions that get a truth value at an earlier stage in KTT. Furthermore, we show that RTT is more restrictive than KTT, as some type restrictions are not needed in KTT and more formulas can be expressed in the latter.

Looking back at the double hierarchy of Russell, Ramsey [10], and Hilbert and Ackermann [6] considered the orders to cause the restrictiveness, and therefore removed them. This removal resulted in Church's Simple Type Theory STT [1]. We show however that orders in RTT correspond to levels of truth in KTT. Hence, KTT can be regarded as the dual of STT where types have been removed and orders are maintained. As RTT is more restrictive than KTT, we can conclude that it is the combination of types and orders that was the restrictive factor in RTT.
\end{abstract}

"Laan is supported by the Co-operation Centre Tilburg and Eindhoven Universities. He is grateful to the Department of Computing Science, University of Glasgow, for their hospitality, and to the Dutch Foundation for Scientific Reasearch (NWO), for their financial support, during the preparation of this article. 


\section{Introduction}

The role of Type Theory in Logic and Mathematics has always been a restrictive one. The need for restrictions was realised at the beginning of this century, when Bertrand Russell showed that Frege's "Begriffschrift" [4], a formalisation of logic, was inconsistent ${ }^{1}$. Russell considered self-application to be the cause of the contradictions, and hence excluded all possibilities of self-application in his Theory of Types $[12,15]$.

As paradoxical sentences in Natural Language play a role similar to that of the paradoxes in Logic and Mathematics, Type Theory also gave a possibility to eliminate the paradoxical sentences (see for instance [9]). Paradoxes moreover have been classified in two categories (see [10]): the logical and the semantical. The famous Russell's paradox is logical whereas the famous liar's paradox is semantical. The semantical paradoxes usually involve the truth predicate $T$ which gives the truth value of a proposition. Tarski [13] shows that truth is undefinable and that having the truth predicate inside the language leads to contradictions. For this reason, he distinguishes between (object-) language and meta-language and allows the truth predicate only at the meta-level. Now, to talk about the truth of sentences in the meta-language, one needs a meta-meta-language and so on. Kripke [7], however, considers Russell's Theory of Types and the Theory of Truth by Tarski to be too restrictive for a proper formalisation of Natural Language and presents a type-free theory where the truth predicate belongs to the language, in which nevertheless the known paradoxes do not occur. Kripke's idea is to follow a certain hierarchy as with Russell but to take the fixed point of his hierarchy of languages to reach a language which has its own truth predicate.

We start this paper by presenting an overview of both Russell's system (in Section 2, using a formalisation presented in [8]) and Kripke's (in Section 3). In Section 4 we carefully compare both theories. As Russell's system is said to be more restrictive than Kripke's, this comparison is carried out by coding Russell's expressions in Kripke's theory. The stronger restrictions in the Ramified Type Theory can be seen clearly: at several parts in the definition of the embedding the reader will notice that some type-theoretic properties of Russell's expressions are mentionned, but not used in this definition. We show that the embedding is conservative, i.e. that truth in Russell's theory and in Kripke's theory are the same, as far as formulas expressible in Russell's (more restrictive) system are concerned.

\section{The Ramified Theory of Types RTT}

In this section we give a short, formal description of Russell's Ramified Theory of Types (RTT). Our formalisation of Russell's theory is the first of its kind and is worth attention. This formalisation is both faithful to Russell's original informal presentation and compatible with the present formulations of type theories. The basic aim of RTT is to exclude the logical paradoxes from logic by eliminating all self-references. An extended philosophical motivation for this theory can be found in "Principia Mathematica" [15], pages 38-55. We will not go into the full details of the formalisation of Russell's theory (these details can be found in [8], the presentation by Russell himself in "Principia" is informal).

In Subsection 2a we introduce propositional functions, the logical formulas of the "naive" system of logic. In Subsection 2b we present a rule to assign a type to some of these propositional functions. The propositional functions that lead to the logical paradoxes are, of course, not typeable. In Subsection $2 c$ substitution for RTT is discussed. This part is rather technical, but we need it in the proof of Lemma 4.7, which is essential in the proof of one of our fundamental results (Theorem 4.8). That is, Lemma 4.7 helps us in showing that KTT can be regarded as a system based on RTT of which the types and not the orders have been removed.

\footnotetext{
${ }^{1}$ An English translation of Russell's letter to Frege in which this inconsistency is described can be found in [5]
} 


\section{2a Propositional Functions}

In this section we shall describe the set of propositions and propositional functions which Whitehead and Russell use in "Principia". We give a modernised, formal definition which corresponds to the description in "Principia".

At the basis of the system of our formalization there is

- an infinite set $\mathcal{A}$ of individual-symbols;

- an infinite set $\mathcal{V}$ of variables;

- an infinite set $\mathcal{R}$ of relation-symbols together with a map a : $\mathcal{R} \rightarrow \mathbb{N}^{+}$(indicating the arity of each relation-symbol).

Since functions are relations in Principia, we will not introduce a special set of function symbols. We assume that $\left\{\mathrm{a}_{1}, \mathrm{a}_{2}, \ldots\right\} \subseteq \mathcal{A} ;\left\{\mathrm{x}, \mathrm{x}_{1}, \mathrm{x}_{2}, \ldots, \mathrm{y}, \mathrm{y}_{1}, \ldots, \mathbf{z}, \mathrm{z}_{1}, \ldots\right\} \subseteq \mathcal{V} ;\left\{\mathrm{R}, \mathrm{R}_{1}, \ldots, \mathrm{S}, \mathrm{s}_{1}, \ldots\right\} \subseteq \mathcal{R}$. We will use the letters $x, y, z, x_{1}, \ldots$ as meta-variables over $\mathcal{V}$, and $R, R_{1}, \ldots$ as meta-variables over $\mathcal{R}$. Note that variables are written in typewriter style and that meta-variables are written in italics: $\mathbf{x}$ denotes one, fixed object in $\mathcal{V}$ whilst $\boldsymbol{x}$ denotes an arbitrary object of $\mathcal{V}$.

We assume that there is an order (e.g. alphabetical) on the collection $\mathcal{V}$, and write $x<y$ if the variable $x$ is ordered before the variable $y$. In particular, we assume that

$$
\mathrm{x}<\mathrm{x}_{1}<\ldots<\mathrm{y}<\mathrm{y}_{1}<\ldots<\mathrm{z}<\mathrm{z}_{1}<\ldots
$$

We also have the logical symbols $\vee, \neg$ and $\forall$ in our alphabet, and the non-logical symbols: parentheses and the comma.

Definition 2.1 (Propositional functions) We define a collection $\mathcal{F}$ of propositional functions, and for each element $f$ of $\mathcal{F}$ we simultaneously define the collection $\mathrm{Fv}(f)$ of free variables of $f$ :

1. If $R \in \mathcal{R}$ and $i_{1}, \ldots, i_{\mathrm{a}(R)} \in \mathcal{A} \cup \mathcal{V}$ then $R\left(i_{1}, \ldots, i_{\mathrm{a}(R)}\right) \in \mathcal{F}$.

$$
\mathrm{FV}\left(R\left(i_{1}, \ldots, i_{\mathrm{a}(R)}\right)\right) \stackrel{\text { def }}{=}\left\{i_{1}, \ldots, i_{\mathrm{a}(R)}\right\} \cap \mathcal{V} ;
$$

2. If $z \in \mathcal{V}, n \in \mathbb{N}$ and $k_{1}, \ldots, k_{n} \in \mathcal{A} \cup \mathcal{V} \cup \mathcal{F}$, then $z\left(k_{1}, \ldots, k_{n}\right) \in \mathcal{F}$. $\mathbf{F V}\left(z\left(k_{1}, \ldots, k_{n}\right)\right) \stackrel{\text { def }}{=}\left\{z, k_{1}, \ldots, k_{n}\right\} \cap \mathcal{V}$.

If $n=0$, we write $z()$ so as to distinguish the propositional function $z()$ from the variable $z{ }^{2}$

3. If $f, g \in \mathcal{F}$ then $f \vee g \in \mathcal{F}$ and $\neg f \in \mathcal{F} . \mathrm{FV}(f \vee g) \stackrel{\text { def }}{=} \mathrm{Fv}(f) \cup \mathrm{FV}(g) ; \mathrm{FV}(\neg f) \stackrel{\text { def }}{=} \mathrm{FV}(f)$;

4. If $f \in \mathcal{F}$ and $x \in \operatorname{Fv}(f)$ then $\forall x[f] \in \mathcal{F}$. $\mathrm{FV}(\forall x[f])=\operatorname{Fv}(f) \backslash\{x\}$.

5. All propositional functions can be constructed by using the rules 1,2, 3 and 4 above.

We use the letters $f, g, h$ as meta-variables over $\mathcal{F}$.

Convention 2.2 (Variable Convention) We make the usual convention that a variable $x$ in a propositional function $f$ that is bound by the quantifier $\forall$ does not occur as a free variable in $f$. Moreover, different bound variables in $f$ have different names.

A propositional function $f$ must be seen as a proposition in which some parts (the free variables) have been left undetermined. It will turn into a proposition as soon as we assign values to all the free variables occurring in it. In this light, a proposition can be seen as a degenerated propositional function (with 0 free variables).

It will be clear now what the intuition behind propositional function of the form $R\left(i_{1}, \ldots, i_{\mathrm{a}(R)}\right)$, $f \vee g, \neg f$ and $\forall x[f]$ is. The intuition behind propositional functions of the second kind is not so obvious. $z\left(k_{1}, \ldots, k_{n}\right)$ is a propositional function of higher order: $z$ is a variable for a propositional

\footnotetext{
${ }^{2}$ It is important to note that a variable is not a propositional function. See for instance [11], Chapter vIII: "The variable", p.94 of the 7 th impression.
} 
function with $n$ free variables; the argument list $k_{1}, \ldots, k_{n}$ indicates what should be substituted ${ }^{3}$ for these free variables as soon as one assigns such a propositional function to $z$.

Example 2.3 Here are some higher-order propositional functions from ordinary mathematics.

- The propositional functions $\mathbf{z}(\mathbf{x})$ and $\mathbf{z}(\mathbf{y})$ in the definition of Leibniz-equality:

$$
\forall z[z(x) \leftrightarrow z(y)]
$$

- The propositional functions $\mathbf{z}(0), \mathbf{z}(\mathbf{x})$ and $\mathbf{z}(\mathrm{y})$ in the formulation of complete induction:

$$
[z(0) \rightarrow(\forall x \forall y[z(x) \rightarrow(S(x, y) \rightarrow z(y))])] \rightarrow \forall x[z(x)]
$$

- $\mathbf{z}()$ in the formulation of the law of the excluded middle:

$$
\forall z[z() \vee \neg z()]
$$

\section{2b Ramified Types}

Not all propositional functions should be allowed in our language. For instance, the expression $\neg x(x)$ is a perfectly legal element of $\mathcal{F}$, nevertheless, it is the propositional function that makes it possible to derive the Russell Paradox. Therefore, types are introduced.

\section{Definition 2.4 (Ramified Types)}

1. $\iota^{0}$ is a ramified type ( 0 is called the order of this type);

2. If $t_{1}, \ldots, t_{n}$ are ramified types of orders $a_{1}, \ldots, a_{n}$ respectively, and $a>\max \left(a_{1}, \ldots, a_{n}\right)$, then $\left(t_{1}, \ldots, t_{n}\right)^{a}$ is a ramified type of order $a$;

3. All ramified types can be constructed using the rules 1 and 2 .

$\iota^{0}$ represents the type of the individuals, and one can think of $\left(t_{1}, \ldots, t_{n}\right)^{a}$ as being the type of the propositional functions with $n$ free variables, say $x_{1}, \ldots, x_{n}$, such that if we assign values $k_{1}$ of type $t_{1}$ to $x_{1}, \ldots, k_{n}$ of type $t_{n}$ to $x_{n}$, then we obtain a proposition. The type ()$^{a}$ stands for the type of propositions of order $a$.

Russell strictly divides his propositional functions in orders. For instance, both $\forall p[p() \vee \neg p()]$ and $\mathrm{R}(\mathrm{a})$ are propositions, but they are of different level: The earlier one presumes a full collection of propositions, hence (according to Russell) it cannot belong to the same collection of propositions as the propositions $\mathrm{p}$ over which it quantifies (among which $\mathrm{R}(\mathrm{a})$ ). This made Russell decide to let $\forall \mathrm{p}[\mathrm{p}() \vee \neg \mathrm{p}()]$ belong to a type of a higher order (level) than the order of $\mathrm{R}(\mathrm{a})$.

This can already be seen in the definition of ramified types: $\left(t_{1}, \ldots, t_{n}\right)^{a}$ can only be a type if $a$ is strictly greater than each of the orders of the $t_{i} \mathrm{~s}$.

Definition 2.5 Let $x_{1}, \ldots, x_{n}$ be a list of distinct variables, and $t_{1}, \ldots, t_{n}$ be a list of ramified types. We call $x_{1}: t_{1}, \ldots, x_{n}: t_{n}$ a context and call $\left\{x_{1}, \ldots, x_{n}\right\}$ its domain.

We write $\Gamma \vdash f: t$ to express that $f \in \mathcal{F}$ has type $t$ in context $\Gamma$, and extend the variable convention to contexts: If $x$ is bound in $f$, then $x$ does not occur in the domain of $\Gamma$.

We use $\Gamma, \Delta$ to range over contexts and $t_{1}, t_{2}, \ldots$ to range over types.

We now present a set of typing rules for RTT. These rules are derived from and equivalent to the rules in [8], which are as close as possible to Russell's original ideas. We change our notation for propositional functions slightly: Instead of $\forall x[f]$ we write $\forall x: t[f]$, where $t$ is some ramified type.

\section{Definition 2.6 (Typing Rules for RTT)}

\footnotetext{
${ }^{3}$ In the Principia, it is not made clear how we should carry out such substitutions. We must depend on our intuition and on the way in which substitution is used in the Principia. Nevertheless, it is hard and elaborate to give a proper definition of substitution. We present a short overview of this definition in Subsection 2c; for a motivation of this definition and its relation to $\beta$-reduction in the $\lambda$-calculus the reader should consult $[8]$.
} 
- If $c \in \mathcal{A}$, then $\Gamma \vdash c: \iota^{0}$ for any context $\Gamma$;

- If $f \in \mathcal{F}$, and $x_{1}<\ldots<x_{n}$ are the free variables of $f$, and $t_{1}, \ldots, t_{n}$ are types such that $x_{i}: t_{i} \in \Gamma$, then $\Gamma \vdash f:\left(t_{1}, \ldots, t_{n}\right)^{a}$ if and only if

- If $f \equiv R\left(i_{1}, \ldots, i_{\mathrm{a}(R)}\right)$ then $t_{i}=\iota^{\circ}$ for all $i$, and $a=1$ (if $n>0$ ) or $a=0$ (if $n=0$ );

- If $f \equiv z\left(k_{1}, \ldots, k_{m}\right)$ then there are $u_{1}, \ldots, u_{m}$ such that $z:\left(u_{1}, \ldots, u_{m}\right)^{a-1} \in \Gamma$, and $\Gamma \vdash k_{i}: u_{i}$ for all $k_{i} \in \mathcal{A} \cup \mathcal{F}$, and $k_{i}: u_{i} \in \Gamma$ for all $k_{i} \in \mathcal{V}$;

- If $f \equiv f_{1} \vee f_{2}$ then there are $u_{1}, u_{2}$ such that $\Gamma \vdash f_{i}: u_{i}$; if $f \equiv \neg f^{\prime}$ then $\Gamma \vdash f^{\prime}:\left(t_{1}, \ldots, t_{n}\right)^{a}$.

- If $f \equiv \forall x: t_{0}\left[f^{\prime}\right]$ then there is $j$ such that $\Gamma, x: t_{0} \vdash f^{\prime}:\left(t_{1}, \ldots, t_{j-1}, t_{0}, t_{j}, \ldots, t_{n}\right)^{a}$.

Example $2.7 \neg x(x)$ is not typeable in any context $\Gamma$.

Assume, we would have $\Gamma \vdash \neg x(x): t$.

Then $t$ must be of the form $(u)^{a}$, with $\mathbf{x}: u \in \Gamma$, as $\neg \mathbf{x}(\mathbf{x})$ has one free variable.

This implies $\Gamma \vdash \mathrm{x}(\mathrm{x}):(u)^{\mathrm{a}}$, hence by Unicity of Types below, $u \equiv\left(u^{\prime}\right)^{a-1}$, with $\mathrm{x}: u^{\prime} \in \Gamma$.

As $\Gamma$ is a context, we have $u \equiv u^{\prime}$, hence $u \equiv(u)^{a-1}$, which is impossible.

An important result is the following (a proof can be found in [8]):

Theorem 2.8 (Unicity of Types) If $\Gamma \vdash f: t$ and $\Gamma \vdash f: u$ then $t \equiv u$.

\section{2c Substitution in RTT}

Substitution in RTT is not simply a syntactic operation of replacing a variable by an object, as is usual in first-order logic. This can be understood if we read the interpretation of the propositional function $z\left(k_{1}, \ldots, k_{m}\right)$. Substituting a propositional function $f$ for the variable $z$ should have as a result $f$, in which $k_{1}, \ldots, k_{m}$ are substituted for the free variables in $f$. So a substitution may result in a new substitution (and we may wonder whether this process will ever terminate). Below, we give a formal definition of substitution in RTT (needed in the proof of the Substitution Lemma 4.7). For examples and an extended motivation of the definition the reader may consult [8].

Definition 2.9 Let $f \in \mathcal{F}, \Gamma \vdash f: t, k_{1}, \ldots, k_{m} \in \mathcal{A} \cup \mathcal{V} \cup \mathcal{F}$ and $x_{1}, \ldots, x_{n} \in \mathcal{V}$ such that

- If $k_{i} \in \mathcal{A}$ then $x_{i}: \iota^{0} \in \Gamma$;

- If $k_{i} \in \mathcal{V}$ then there is $t$ such that both $k_{i}: t \in \Gamma$ and $x_{i}: t \in \Gamma$;

- If $k_{i} \in \mathcal{F}$ then there is $t$ such that $\Gamma \vdash k_{i}: t$ and $x_{i}: t \in \Gamma$.

We define $f\left[x_{1}, \ldots, x_{m}:=k_{1}, \ldots, k_{m}\right]$, the (simultaneous) substitution of $k_{1}, \ldots, k_{m}$ for $x_{1}, \ldots, x_{m}$ in $f$ (shorthand $f\left[x_{i}:=k_{i}\right]$ if no confusion arises) by a double induction on the order and structure of $f$ :

- $f \equiv R\left(i_{1}, \ldots, i_{\mathrm{a}(R)}\right)$. Define $i_{j}^{\prime} \stackrel{\text { def }}{=} \begin{cases}k_{\ell} & \text { if } i_{j} \equiv x_{\ell} \\ i_{j} & \text { if } i_{j} \notin\left\{x_{1}, \ldots, x_{m}\right\}\end{cases}$ $f\left[x_{i}:=k_{i}\right] \stackrel{\text { def }}{=} R\left(i_{1}^{\prime}, \ldots, i_{\mathrm{a}(R)}^{\prime}\right)$.

- $f \equiv z\left(h_{1}, \ldots, h_{n}\right)$. We distinguish two cases:

1. $z \notin\left\{x_{1}, \ldots, x_{m}\right\}$. Define $h_{j}^{\prime} \stackrel{\text { def }}{=} \begin{cases}k_{\ell} & \text { if } h_{j} \equiv x_{\ell} \\ h_{j} & \text { if } h_{j} \notin\left\{x_{1}, \ldots, x_{m}\right\}\end{cases}$ $f\left[x_{i}:=k_{i}\right] \stackrel{\text { def }}{=} z\left(h_{1}^{\prime}, \ldots, h_{n}^{\prime}\right)$.

2. $z \in\left\{x_{1}, \ldots, x_{m}\right\}$, assume $z \equiv x_{p}$. Define $h_{j}^{\prime} \stackrel{\text { def }}{=} \begin{cases}k_{\ell} & \text { if } h_{j} \equiv x_{\ell} \\ h_{j} & \text { if } h_{j} \notin\left\{x_{1}, \ldots, x_{m}\right\}\end{cases}$

Notice that, as $z, x_{p}$ and $k_{p}$ have the same type, $k_{p}$ is a propositional function with $n$ free variables, say $y_{1}<\ldots<y_{n}$. Now: $f\left[x_{i}:=g_{i}\right] \stackrel{\text { def }}{=} k_{p}\left[y_{1}, \ldots, y_{n}:=h_{1}^{\prime}, \ldots, h_{n}^{\prime}\right]$. Note that the object on the right is a correct substitution (with respect to the types of the $y_{j}$ and the $h_{j}^{\prime}$ ) and has already been defined, as $k_{p}$ has the same order as $z$, which is exactly one less than the order of $z\left(h_{1}, \ldots, h_{n}\right)$. 
- $f \equiv f_{1} \vee f_{2}$. Then $f\left[x_{i}:=k_{i}\right] \stackrel{\text { def }}{=} f_{1}\left[x_{i}:=k_{i}\right] \vee f_{2}\left[x_{i}:=k_{i}\right]$.

- $f \equiv \neg f^{\prime}$. Then $f\left[x_{i}:=k_{i}\right] \stackrel{\text { def }}{=} \neg f^{\prime}\left[x_{i}:=k_{i}\right]$.

- $f \equiv \forall x: t\left[f^{\prime}\right]$. Then $f\left[x_{i}:=k_{i}\right] \stackrel{\text { def }}{=} \forall x: t\left[f^{\prime}\left[x_{i}:=k_{i}\right]\right]$ (we assume that $x \notin\left\{x_{1}, \ldots, x_{m}\right\}$ ).

We will need the following results about substitutions. They are proved in [8].

Lemma 2.10 The order of $f$ is greater than or equal to the order of the substitution $f\left[x_{i}:=k_{i}\right]$.

Lemma $2.11 \mathrm{FV}\left(f\left[x_{i}:=g_{i}\right]\right)=\left(\mathrm{FV}(f) \backslash\left\{x_{1}, \ldots, x_{n}\right\}\right) \cup\left\{g_{i} \mid g_{i} \in \mathcal{V}\right.$ and $\left.x_{i} \in \mathrm{FV}(f)\right\}$

\section{2d Logical Truth for RTT in Tarski's Style}

With substitution properly defined, we can give a definition of logical truth in Tarski-style for RTT:

Definition 2.12 (Logical Truth for RTT) Let $f \in \mathcal{F}$ and assume $\mathrm{Fv}(f)=\varnothing$. We define $\mathrm{RTT} \vDash f$ :

- If $\left(a_{1}, \ldots, a_{m}\right) \in R$ then $\operatorname{RTT} \models R\left(a_{1}, \ldots, a_{m}\right)$.

- If $\operatorname{RTT} \vDash f_{1}$ or $\operatorname{RTT} \vDash f_{2}$ then $\operatorname{RTT} \vDash f_{1} \vee f_{2}$.

- If $\operatorname{not} \operatorname{RTT} \vDash f$, then $\operatorname{RTT} F-f$.

- If $f \equiv \forall x: t[h]$ and for all $g \in \mathcal{F}$ of type $t$, RTT $\models h[x:=g]^{4}$, then RTT $\models \forall x: t[h]$.

\section{Kripke's Theory of Truth KTT}

In this section, we shortly describe Kripke's Theory of Truth KTT (see [7]). Kripke expresses higher-order formulas within a first-order language, using the fact that many interesting languages are rich enough to express their own syntax (for instance, via a Gödel Numbering).

Let us assume a first-order language $L$, with variables ranging over a domain $D$, and primitive predicates interpreted by (totally defined) relations on $D$. Let us also assume two subsets $S_{1}$ and $S_{2}$ of $D$ such that $S_{1} \cap S_{2}=\varnothing$. Kripke extends $L$ to $L\left(S_{1}, S_{2}\right)$ by adding a monadic predicate $\mathbf{T}$. The main idea is to interpret T as a "truth predicate". $S_{1}$ contains the elements $d$ of $D$ for which $\mathrm{T}(d)$ holds (so it contains the (codes of) formulas which we consider to be "true"); $S_{2}$ contains those $d \in D$ for which $\neg \mathrm{T}(d)$ holds (hence it contains the (codes of) formulas which we consider to be "false"). We do not demand that $S_{1} \cup S_{2}=D$, hence $\mathrm{T}$ is a partial predicate over $D$.

Definition 3.1 (Logical Truth for KTT) Let $L$ be a first-order language over a domain $D$ with $\mathcal{R}$ as set of primitive predicates. Let $f$ be a sentence in $L$. We define $L \models f$ as follows ${ }^{5}$ :

\begin{tabular}{c||c|c}
$f$ & $L \models f$ & $L \models \neg f$ \\
\hline$R\left(d_{1}, \ldots, d_{m}\right)$ & $\left(d_{1}, \ldots, d_{m}\right) \in R$ & $\left(d_{1}, \ldots, d_{m}\right) \notin R$ \\
$g_{1} \wedge g_{2}$ & $L \vDash g_{1}$ and $L \models g_{2}$ & $L \models\left(\neg g_{1}\right) \vee\left(\neg g_{2}\right)$ \\
$g_{1} \vee g_{2}$ & $L \models g_{1}$ or $L \models g_{2}$ & $L \models\left(\neg g_{1}\right) \wedge\left(\neg g_{2}\right)$ \\
$\forall x[g]$ & $L \models g[x:=d]$ for all $d \in D$ & $L \models \exists x[\neg g]$ \\
$\exists x[g]$ & $L \models g[x:=d]$ for some $d \in D$ & $L \models \forall x[\neg g]$ \\
$\neg \neg g$ & $L \models g$ & $L \models \neg g$
\end{tabular}

Here, $R \in \mathcal{R} ; d, d_{1}, \ldots, d_{m} \in D$, and $g, g_{1}, g_{2}$ are formulas of $L$. Now let $S_{1}, S_{2} \subseteq D$ such that $S_{1} \cap S_{2}=\varnothing$. KTT $\equiv L\left(S_{1}, S_{2}\right)$ is the first order language over $D$ with $\mathcal{R} \cup\{\mathbf{T}\}$ as the set of primitive predicates $(\mathrm{T} \notin \mathcal{R})$. We extend the definition of $L \vDash f$ to KTT $\models f$ by putting KTT $\models \mathrm{T}(d)$ iff $d \in S_{1}$ and KTT $\models \neg \mathrm{T}(d)$ iff $d \in S_{2}$.

\footnotetext{
${ }^{4} \mathrm{Fv}(h[x:=g])=\varnothing$ by Lemma 2.11

${ }^{5}$ Notice that even though this definition is different from Tarski's definition, especially with respect to the definition of $L \models \neg f$, it is easy to prove the equivalence of both definitions. This is because all primitive predicates of $L$ are totally defined. We took this definition however as we need to extend it for the partial predicate $\mathrm{T}$.
} 
It is important (and easy) to notice that the extension of $L$ to $L\left(S_{1}, S_{2}\right)$ is conservative:

Lemma 3.2 Let $L$ be a first order language over a domain $D$, let $S_{1}, S_{2} \subseteq D$ such that $S_{1} \cap S_{2}=\varnothing$, and assume that $f$ is a sentence in $L$. Then $L \models f$ if and only if $L\left(S_{1}, S_{2}\right) \models f$.

Now Kripke uses $T$ as a predicate expressing truth by defining a hierarchy of languages. This hierarchy has much in common with Russell's hierarchy of orders. $L$ was assumed to be able to express its own syntax, hence so is $L\left(S_{1}, S_{2}\right)$, for any $S_{1}, S_{2}$. Notice that the sentences of $L\left(S_{1}, S_{2}\right)$ do not depend on the sets $S_{1}$ and $S_{2}$, so we can take one Gödel Numbering \langle\rangle , being a map from the formulas of $L\left(S_{1}, S_{2}\right)$ to $D$. The Kripke-hierarchy of languages is defined by presenting a hierarchy of pairs of sets $\left(S_{1}, S_{2}\right)$ :

Definition 3.3 For any ordinal $\alpha$ we define a pair of sets $\left(S_{\alpha, 1}, S_{\alpha, 2}\right)$ and a language KтT . $_{\alpha}$.

- $S_{0,1} \stackrel{\text { def }}{=} \varnothing ; S_{0,2} \stackrel{\text { def }}{=} \varnothing ; \mathrm{KTT}_{0} \stackrel{\text { def }}{=} L\left(S_{0,1}, S_{0,2}\right)$.

- If $S_{\alpha, 1}, S_{\alpha, 2}$ and KTT $\alpha$ have been defined, then we define:

$$
\begin{array}{rll}
S_{\alpha+1,1} & \stackrel{\text { def }}{=} & \left\{\langle f\rangle \mid f \text { is a sentence and } \mathrm{KTT}_{\alpha} \vDash f\right\} \\
S_{\alpha+1,2} & \stackrel{\text { def }}{=}\left\{\langle f\rangle \mid f \text { is a sentence and } \mathrm{KTT}_{\alpha} \vDash \neg f\right\} \cup \\
& \cup & \left\{d \in D \mid d \not \equiv\langle f\rangle \text { for all sentences } f \text { of } \mathrm{KTT}_{\alpha}\right\} \\
\mathrm{KTT}_{\alpha+1} & \stackrel{\text { def }}{=} & L\left(S_{\alpha+1,1}, S_{\alpha+1,2}\right)
\end{array}
$$

- If $\alpha$ is a limit ordinal and $S_{\beta, 1}, S_{\beta, 2}$ and KTT $_{\beta}$ have been defined for all $\beta<\alpha$, then

$$
\begin{aligned}
S_{\alpha, i} & \stackrel{\text { def }}{=} \bigcup_{\beta<\alpha} S_{\beta, i} \\
\mathrm{KTT}_{\alpha} & \stackrel{\text { def }}{=} L\left(S_{\alpha, 1}, S_{\alpha, 2}\right)
\end{aligned}
$$

Lemma 3.4 (Conservation of Knowledge) If $\alpha<\beta$ then $S_{\alpha, 1} \subseteq S_{\beta, 1}$ and $S_{\alpha, 2} \subseteq S_{\beta, 2}$.

We can see the construction of the languages $\mathrm{KTT}_{\alpha}$ as a process of obtaining knowledge. At the initial stage, $\mathrm{KTT}_{0}, \mathbf{T}(d)$ is not defined for any $d \in D$. There is no knowledge at all.

Applying the definition of truth given for KTT0, we obtain knowledge: Some sentences $f$ can be judged true ( $\mathrm{KTT}_{0} \vDash f$; we store the code of $f$ in $S_{1,1}$ ), some other sentences $g$ can be judged false ( $\mathrm{KTT}_{0} \vDash \neg g$; the code of $g$ is stored in $S_{1,2}$ ). It is not possible to judge all sentences. For instance, neither $\mathrm{KTT}_{0} \vDash \forall \mathrm{x}[\mathrm{T}(\mathrm{x}) \vee \neg \mathrm{T}(\mathrm{x})]$ nor $\mathrm{KTT}_{0} \vDash \neg \forall \mathrm{x}[\mathrm{T}(\mathrm{x}) \vee \neg \mathrm{T}(\mathrm{x})]$ hold, so $\langle\forall \mathrm{x}[\mathrm{T}(\mathrm{x}) \vee \neg \mathrm{T}(\mathrm{x})]\rangle$ neither belongs to $S_{1,1}$, nor to $S_{1,2}$.

The knowledge we obtained is expressed by the predicate $\mathrm{T}$ in $\mathrm{KTT}_{1}$. In $\mathrm{KTT}_{1}$ we know more about $\mathrm{T}$ than in $\mathrm{KTT}_{0}$. Hence more sentences can be judged true or false; we store their codes in $S_{2,1}$ and $S_{2,2}$ respectively. The Lemma on Conservation of Knowledge 3.4 guarantees that this process only extends our knowledge, i.e.:

- Sentences that were judged to be true at level KтT $\mathrm{K}_{1}$ remain true at level $\mathrm{KTT}_{2}$;

- Sentences that were judged to be false at level $\mathrm{KTT}_{1}$ remain false at level $\mathrm{KTT}_{2}$.

By iterating this process we arrive at the levels $\mathrm{KTT}_{3}, \mathrm{KTT}_{4}, \ldots, \mathrm{KTT}_{\omega}, \mathrm{KTT}_{\omega+1}, \ldots$. This limit does terminate however in that it has a fixed point.

\section{RTT in KTT}

Both in RTT and in KTT we are confronted with a hierarchy. Russell constructs a hierarchy by dividing propositions and propositional functions into different orders, taking care that a propositional function $f$ can only depend on objects of a lower order than the order of $f$. 
Kripke does not make this distinction beforehand. He has only one truth-predicate (T), but decisions about truth of propositions are split into different levels: At the first level only decisions about propositions that do not involve $\mathrm{T}$ are made, at the second level decisions about propositions involving $T$ for codes of first-level propositions are made, and so on.

In subsection $4 \mathrm{a}$ we investigate the similarity between both hierarchies, by describing RTT within KTT. In subsection $4 \mathrm{~b}$ we investigate in which way RTT is more restrictive with respect to selfreference than KTT.

\section{4a RTT embedded in KTT}

To embed RTT in a first order language $L$, we have to cope with two technical problems:

- We need to encode the notion of and the manipulation with (higher-order) propositional functions into a first-order language. The manipulation is especially important with respect to substitution, which in the higher-order situation is much more complicated than in the first order case (cf. the definition of substitution 2.9).

- In Russell's theory, it is possible (and, due to the hierarchy of orders, in fact only possible) to quantify over only a part of all propositions. This makes it impossible to translate, for instance, the proposition $\forall \mathrm{p}:()^{1}[\mathrm{p}() \vee \neg \mathrm{p}()]$ directly by $\forall \mathrm{x}[\mathrm{T}(\mathrm{x}) \vee \neg \mathrm{T}(\mathrm{x})]$, as the quantifier in the latter also quantifies over (codes of) higher-order propositions.

As we do not want contexts to be involved in this coding, we assume that each variable in $\mathcal{V}$ has (implicitly) a superscript $t$, indicating its type. This makes it possible to do without contexts, as the types of the variables are now clear from the function in which they occur. For reasons of clarity, we will not write this superscript explicitly, as long as no confusion arises.

We propose the following solutions to the problems sketched above (we first give the definition and afterwards explain our thoughts behind it):

Definition 4.1 Let KTT be the language $L$ with domain $D=\mathcal{A}$, extended with for each ramified type $t$ a monadic predicate $\mathrm{Typ}_{t}$, for each $n \in \mathbb{N}$ a $(n+1)$-ary predicate $\mathrm{App}_{n}$, and the predicate $\mathrm{T}$ ( $\mathrm{T}$ will play the same role as in Section 3). We code the typeable propositional functions $f$ of $\mathcal{F}$ to formulas $\bar{f}$ in the language KTT. We do this by induction on the structure of $f$.

- If $f \equiv R\left(i_{1}, \ldots, i_{\mathrm{a}(R)}\right)$, then $f$ is present in the original language $L$ and we take $\bar{f} \stackrel{\text { def }}{=} f$.

- If $f \equiv z\left(k_{1}, \ldots, k_{m}\right)$, write $K_{i} \equiv\left\langle\overline{k_{i}}\right\rangle$ for $k_{i} \in \mathcal{F}$, and $K_{i} \equiv k_{i}$ for $k_{i} \in \mathcal{A} \cup \mathcal{V}$. Define $\bar{f} \stackrel{\text { def }}{=} \mathrm{T}\left(\mathrm{App}_{m}\left(z, K_{1}, \ldots, K_{m}\right)\right)$.

- If $f \equiv f_{1} \vee f_{2}$, then $\bar{f} \stackrel{\text { def }}{=} \overline{f_{1}} \vee \overline{f_{2}}$.

- If $f \equiv \neg f^{\prime}$, then $\bar{f} \stackrel{\text { def }}{=} \neg \overline{f^{\prime}}$.

- If $f \equiv \forall x: u\left[f^{\prime}\right]$, then $\bar{f} \stackrel{\text { def }}{=} \forall x\left[\neg \operatorname{TyP}_{u}(x) \vee \overline{f^{\prime}}\right]$.

We now give a formal interpretation to the newly introduced predicates $\mathrm{TyP}_{t}$ and $\mathrm{App}_{n}$.

Definition 4.2 For all ramified types $t \neq \iota^{0}$, let $\operatorname{Typ}_{t} \stackrel{\text { def }}{=}\{\langle\bar{f}\rangle \mid f \in \mathcal{F}$ and $f: t\}$ and $\operatorname{Typ}_{t^{\circ}} \stackrel{\text { def }}{=} D$. Assume: $n \in \mathbb{N}, f \in \mathcal{F}$ is of type $\left(t_{1}, \ldots, t_{n}\right)$ and has free variables $x_{1}<\ldots<x_{n}$. Assume also: for $i=1, \ldots, n, k_{i}: t_{i}$ and either $d_{i}=k_{i}$ (if $t_{i}=\iota^{0}$ ) or $d_{i}=\left\langle\overline{k_{i}}\right\rangle\left(\right.$ if $t_{i} \neq \iota^{0}$ ). We define:

$$
\operatorname{App}_{n}\left(\langle\bar{f}\rangle, d_{1}, \ldots, d_{n}\right) \stackrel{\text { def }}{=}\left\langle\overline{f\left[x_{1}, \ldots, x_{n}:=k_{1}, \ldots, k_{n}\right]}\right\rangle .
$$

We make some remarks with respect to these definitions.

Remark 4.3 It is clear that the newly introduced predicates $\mathrm{App}_{n}$ are used for carrying out substitutions, thus solving the first of the technical problems stated at the beginning of this subsection. The predicates $\mathrm{TyP}_{t}$ solve the second problem, as can be seen in the definition of $\overline{\forall x[f]}$. 
Remark 4.4 Notice that we did not define the functions $\mathrm{App}_{n}$ on the full domain $D^{n+1}$. We could have done that, but will not need $\mathrm{App}_{n}$ on other elements of $D^{n+1}$ than defined above.

Remark 4.5 The extensions suggested above are of a mere technical character. Therefore, we think that we can still speak of an embeddimg of RTT within KTT.

Notation 4.6 To keep notations uniform, we sometimes want to speak about $\langle\bar{x}\rangle$ when we only intend to mention $x$, for $x \in \mathcal{V}$, and about $\langle\bar{a}\rangle$ when only meaning $a$, for $a \in \mathcal{A}$. Hence, we formally define: $\langle\bar{x}\rangle \stackrel{\text { def }}{=} x$ and $\langle\bar{a}\rangle \stackrel{\text { def }}{=} a$ for all $x \in \mathcal{V}$ and all $x \in \mathcal{A}$.

Below, we work in two systems: RTT and KTT. These systems have a different notion of substitution, though they use the same notation for expressing substitution. From the context, however, it will always be clear which kind of substitution is meant.

The language KTT above is similar to that presented in Section 3 , and we construct $\mathrm{KTT}_{\alpha}$ for each ordinal $\alpha$ as described in that section. We need the following lemma:

Lemma 4.7 (Substitution Lemma) Assume $g$ is a propositional function of order $m$ and $g[x:=k]$ is a proposition of order $n$. If $\mathrm{KTT}_{n} \vDash \overline{g[x:=k]}$ then $\mathrm{KTT}_{m} \vDash \bar{g}[x:=\langle\bar{k}\rangle]$.

Proof: We make the proof a little easier by proving that if: If $g$ is a propositional function of order $m$ and $g\left[x_{1}, \ldots, x_{p}:=k_{1}, \ldots, k_{p}\right]$ is a proposition of order $n$, then 1 and 2 hold where

1. $\operatorname{KTT}_{n} \vDash \overline{g\left[x_{1}, \ldots, x_{p}:=k_{1}, \ldots, k_{p}\right]} \operatorname{implies}_{\operatorname{KTT}_{m}}=\bar{g}\left[x_{1}, \ldots, x_{p}:=\left\langle\overline{k_{1}}\right\rangle, \ldots,\left\langle\overline{k_{p}}\right\rangle\right]$

2. $\operatorname{KTT}_{n} \vDash \overline{\neg g\left[x_{1}, \ldots, x_{p}:=k_{1}, \ldots, k_{p}\right]}$ implies $\operatorname{KTT}_{m} \vDash \overline{\neg g}\left[x_{1}, \ldots, x_{p}:=\left\langle\overline{k_{1}}\right\rangle, \ldots,\left\langle\overline{k_{p}}\right\rangle\right]$

We write $g\left[x_{i}:=k_{i}\right]$ as a shorthand for $g\left[x_{1}, \ldots, x_{p}:=k_{1}, \ldots, k_{p}\right]$ as long as no confusion arises, and use similar abbreviations for other substitutions. The proof is by induction on the structure of $g$.

- $g \equiv R\left(i_{1}, \ldots, i_{\mathrm{a}(R)}\right)$. Then, by definition of $g\left[x_{i}:=k_{i}\right], \overline{g\left[x_{i}:=k_{i}\right]} \equiv \bar{g}\left[x_{i}:=\left\langle\overline{k_{i}}\right\rangle\right]$. As $n \leq m$, the lemma follows by the Lemma on Conservation of Knowledge 3.4.

- $g \equiv z\left(h_{1}, \ldots, h_{q}\right)$. If $z \notin\left\{x_{1}, \ldots, x_{p}\right\}$ then again $\overline{g\left[x_{i}:=k_{i}\right]} \equiv \bar{g}\left[x_{i}:=\left\langle\overline{k_{i}}\right\rangle\right]$ and again the lemma follows from $n \leq m$ and the Lemma on Conservation of Knowledge 3.4.

The interesting case is when $g \equiv z\left(h_{1}, \ldots, h_{q}\right)$ and $z \in\left\{x_{1}, \ldots, x_{p}\right\}$. To keep notations clear, we assume $p=1$ and $z=x_{1}$. The reader may verify that the case $p>1$ only complicates notation, not the proof. We only show 1 as 2 is similar. Assume KTT $\mathrm{K}_{n} \models \overline{g\left[x_{i}:=k_{i}\right]}$.

As $k_{1}$ and $z$ have the same type, $k_{1}$ has $q$ free variables, say $y_{1}<\ldots<y_{q}$, and by definition of substitution in RTT, $z\left(h_{1}, \ldots, h_{q}\right)\left[x_{1}:=k_{1}\right] \equiv k_{1}\left[y_{i}:=h_{i}\right]$. Notice that $z$ and $k_{1}$ have the same order $(m-1)$, and that $n$, the order of $k_{1}\left[y_{i}:=h_{i}\right]$, is at most the order of $k_{1}$ (Lemma 2.10). This means: $n \leq m-1$. Using Lemma 3.4: $\mathrm{KTT}_{m-1} \models \overline{k_{1}\left[y_{i}:=\overline{\left.h_{i}\right]}\right.}$.

By the definition of $\mathrm{T}$ we have: $\mathrm{KTT}_{m} \vDash \mathrm{T}\left(\left\langle\overline{k_{1}\left[y_{i}:=h_{i}\right]}\right\rangle\right)$. We are now done because:

$$
\begin{aligned}
\bar{g}\left[x_{1}:=\left\langle\overline{k_{1}}\right\rangle\right] & \equiv \overline{z\left(\overline{\left.h_{1}, \ldots, h_{q}\right)}\right.}\left[z:=\left\langle\overline{k_{1}}\right\rangle\right] \\
& \equiv \mathrm{T}\left(\operatorname{App}_{q}\left(z,\left\langle\overline{h_{1}}\right\rangle, \ldots,\left\langle\overline{h_{q}}\right\rangle\right)\right)\left[z:=\left\langle\overline{k_{1}}\right\rangle\right] \\
& \equiv \mathrm{T}\left(\operatorname{App}_{q}\left(\left\langle\overline{k_{1}}\right\rangle,\left\langle\overline{h_{1}}\right\rangle, \ldots,\left\langle\overline{h_{q}}\right\rangle\right)\right) \\
& \equiv \mathrm{T}\left(\left\langle\overline{k_{1}\left[y_{i}:=h_{i}\right]}\right\rangle\right)
\end{aligned}
$$

- $g \equiv g_{1} \vee g_{2}$.

First, assume $\mathrm{KTT}_{n} \vDash \overline{g\left[x_{i}:=k_{i}\right]}$. As $\overline{g\left[x_{i}:=k_{i}\right]} \equiv \overline{g_{1}\left[x_{i}:=k_{i}\right]} \vee \overline{g_{2}\left[x_{i}:=k_{i}\right]}$, there is $j$ such that $\mathrm{KTT}_{n} \vDash \overline{g_{j}\left[x_{i}:=k_{i}\right]}$. By the induction hypothesis, there is $j$ such that $\mathrm{KTT}_{m} \vDash \overline{g_{j}}\left[x_{i}:=\left\langle\overline{k_{i}}\right\rangle\right]$, as the order of $g_{j}$ is $\leq m$. Hence $\mathrm{KTT}_{m} \vDash \overline{g_{1}}\left[x_{i}:=\left\langle\overline{k_{i}}\right\rangle\right] \vee \overline{g_{2}}\left[x_{i}:=\left\langle\overline{k_{i}}\right\rangle\right]$, so we are done.

Now assume $\operatorname{KTT}_{n} \models \overline{\neg g\left[x_{i}:=k_{i}\right]}$. This means: $\mathrm{KTT}_{n} \vDash \neg\left(\overline{g_{1}\left[x_{i}:=k_{i}\right]} \vee \overline{g_{2}\left[x_{i}:=k_{i}\right]}\right)$.

Hence $\operatorname{KTT}_{n} \vDash \neg \overline{g_{j}\left[x_{i}:=k_{i}\right]}$ for $j=1,2$, and by the induction hypothesis, this means (again the order of the $g_{j}$ s are $\left.\leq m\right) \mathrm{KTT}_{m} \models \neg \overline{g_{j}}\left[x_{i}:=\left\langle\overline{k_{i}}\right\rangle\right]$ for $j=1,2$, hence

$\mathrm{KTT}_{m} \vDash \neg \overline{g_{1}}\left[x_{i}:=\left\langle\overline{k_{i}}\right\rangle\right] \wedge \neg \overline{g_{2}}\left[x_{i}:=\left\langle\overline{k_{i}}\right\rangle\right]$.

So KтT $m \vDash \neg\left(\overline{g_{1}}\left[x_{i}:=\left\langle\overline{k_{i}}\right\rangle\right] \vee \overline{g_{2}}\left[x_{i}:=\left\langle\overline{k_{i}}\right\rangle\right]\right)$, and $\operatorname{KTT}_{m} \vDash\left(\neg\left(g_{1} \vee g_{2}\right)\right)\left[x_{i}:=\left\langle\overline{k_{i}}\right\rangle\right]$. 
- $g \equiv \neg g^{\prime}$.

If $\operatorname{KTT}_{n} \vDash \overline{g\left[x_{i}:=k_{i}\right]}$ then use the induction hypothesis for $g^{\prime}$.

If $\mathrm{KTT}_{n} \vDash \neg g\left[x_{i}:=k_{i}\right]$ then $\mathrm{KTT}_{n} \vDash \overline{g^{\prime}\left[x_{i}:=k_{i}\right]}$, so by induction $\mathrm{KTT}_{m} \vDash \overline{g^{\prime}}\left[x_{i}:=\left\langle\overline{k_{i}}\right\rangle\right]$, so $\operatorname{KTT}_{m} \vDash \overline{\neg \neg g^{\prime}}\left[x_{i}:=\left\langle\overline{k_{i}}\right\rangle\right]$.

- $g \equiv \forall x: t\left[g^{\prime}\right]$.

If $\operatorname{KTT}_{n} \vDash g\left[x_{i}:=k_{i}\right]$, then for all $d$ such that $\operatorname{Typ}_{t}(d), \operatorname{KTT}_{n} \vDash \overline{g^{\prime}\left[x_{i}:=k_{i}\right]}[x:=d]$, hence for all these $d, \mathrm{KTT}_{m} \vDash \overline{g^{\prime}}\left[x_{i}:=\left\langle\overline{k_{i}}\right\rangle\right][x:=d]$, so KTT $m \vDash \forall x\left[\overline{g^{\prime}}\left[x_{i}:=\left\langle\overline{k_{i}}\right\rangle\right]\right]$, and $\operatorname{KTT}_{m} \vDash \bar{g}\left[x_{i}:=\left\langle\overline{k_{i}}\right\rangle\right]$.

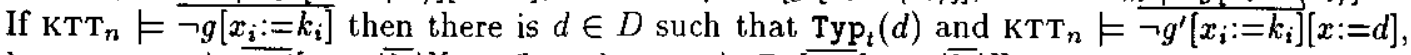
hence $\mathrm{KTT}_{m} \vDash \overline{\neg g^{\prime}}\left[x_{i}:=\left\langle\overline{k_{i}}\right\rangle\right][x:=d]$, and $\mathrm{KTT}_{m} \vDash \exists x\left[\overline{\neg g^{\prime}}\left[x_{i}:=\left\langle\overline{k_{i}}\right\rangle\right]\right]$.

Hence $\mathrm{KTT}_{m} \vDash \exists x\left[\neg \overline{g^{\prime}}\left[x_{i}:=\left\langle\overline{k_{i}}\right\rangle\right]\right]$ and $\mathrm{KTT}_{m} \vDash \neg \forall x\left[\overline{g^{\prime}}\left[x_{i}:=\left\langle\overline{k_{i}}\right\rangle\right]\right]$.

Theorem 4.8 Let $f:()^{n} \in \mathcal{F}$. Then: $\operatorname{RTT} \vDash f$ if and only if $\mathrm{KTT}_{n} \vDash \bar{f}$.

Proof:

$\Leftarrow$ Due to the use of $\neg$ in the definition of $\operatorname{KTT}_{n} \vDash \bar{f}$, we prove a little bit more:

- If $\operatorname{RTT} \vDash f$ then $\operatorname{KTT}_{n} \vDash \bar{f}$;

- If RTT $\models \neg f$ then $\operatorname{KTT}_{n} \models \overline{\neg f}$.

These claims are proved simultaneously by induction on the definition of RTT $\models f$.

- $f \equiv R\left(d_{1}, \ldots, d_{\mathrm{a}(R)}\right)$ for a $R \in \mathcal{R}$ and some $d_{1}, \ldots, d_{\mathrm{a}(R)} \in D$. Then $\bar{f} \equiv f$. As RTT $\models f$, we know that $\left(d_{1}, \ldots, d_{\mathrm{a}(R)}\right) \in R$, hence $\mathrm{KTT}_{n} \vDash \bar{f}$. The proof is similar for $\neg f$.

- $f \equiv g_{1} \vee g_{2}$. Then the orders of the $g_{i}$ s are either equal to, or smaller than $n$.

First assume RTT $\models f$. Then we know that RTT $\models g_{i}$ for $i=1$ or $i=2$. By the induction hypothesis (and Conservation of Knowledge, if the order of $g$ is $\left\langle n\right.$ ), $\mathrm{KTT}_{n} \vDash \overline{g_{i}}$, As $\bar{f} \equiv \overline{g_{1}} \vee \overline{g_{2}}, \mathrm{KTT}_{n} \vDash \bar{f}$.

Now assume RTT $\models \neg f$. Then it is not true that RTT $\models f$, so it is not true that RTT $\models g_{i}$ for $i=1$ or $i=2$. So RTT $\vDash \neg g_{i}$ for $i=1,2$. By the induction hypothesis (and, again, possibly Conservation of Knowledge), we have $\mathrm{KTT}_{n} \vDash \overline{\neg g_{i}}$, hence, $\mathrm{KTT}_{n} \vDash \neg \overline{g_{i}}$ for $i=1,2$. So $\operatorname{KTT}_{n} \models \neg \overline{g_{1}} \wedge \neg \overline{g_{2}}$, and hence so $\operatorname{KTT}_{n} \models \overline{\neg f}$.

- $f \equiv \neg g$. If RTT $\vDash f$ then use IH on $g$ to get $\operatorname{KTT}_{n} \models \bar{\neg}$, hence $\operatorname{KTT}_{n} \vDash \bar{f}$.

If $\operatorname{RTT} \vDash \neg f$, then $\operatorname{RTT} \vDash g$, so by induction $\operatorname{KTT}_{n} \vDash \bar{g}$, so KTT $\vDash \neg \neg \bar{g}$, so $\mathrm{KTT}_{n} \vDash \overline{\neg f}$.

- $f \equiv \forall x: t[g]$. Notice that $g$ has order $n$.

If RTT $\models f$ then for all $k: t$, RTT $\models g[x:=k]$. By the induction hypothesis, we know that for all $k: t, \mathrm{KTT}_{m_{k}} \vDash \overline{g[x:=k]}$, where $m_{k}$ is the order of $g[x:=k]$.

By the Substitution Lemma 4.7 we have: For all $k: t, \operatorname{KTT}_{n} \vDash \bar{g}[x:=\langle\bar{k}\rangle]$. Hence, for all $d \in D, \operatorname{KTT}_{n} \vDash \neg \operatorname{Typ}_{t}(d) \vee g(d)$. Hence $\mathrm{KTT}_{n} \vDash \overline{\forall x: t[g]}$.

The argument for RTT $=\neg f$ is similar.

$\Rightarrow$ This is easy now. Assume, for the sake of the argument, not RTT $\models f$. Then RTT $\models \neg f$, hence $\mathrm{KTT}_{n} \vDash \neg \bar{f}$ and $\mathrm{KTT}_{n} \models \bar{f}$, which is a contradiction.

This theorem clearly shows the relation between the orders in RTT and the levels of truth in KTT. The heart of the proof of Theorem 4.8 is in the proof of case $z\left(h_{1}, \ldots, h_{q}\right)$ of the Substitution Lemma 4.7. This is the only place in the proof where the properties of the predicate $T$ are used. It is understandable that these properties must be used at exactly this place when we look at the definition of propositional functions and the typing rules for propositional functions. Exactly the possibility of constructing a propositional function of the form $z\left(h_{1}, \ldots, h_{q}\right)$ makes it possible to arrive at higher-order propositional functions and higher-order propositions. So exactly at this spot, Kripke's predicate $\mathrm{T}$ must appear, in order to raise one level in KTT as well.

Corollary 4.9 RTT $\models f$ if and only if $\mathrm{KTT}_{\omega^{\prime}} \vDash \bar{f}$.

We cannot improve the result of Theorem 4.8 in general: There are propositions $f$ of order $n$ in RTT whose code is provable at level $\mathrm{KTT}_{n}$ in $\mathrm{KTT}$, but not at any lower level. 
Theorem 4.10 Let $n>0$, and let $f_{n}$ be the nth-order-proposition $\forall \mathrm{p}:()^{n-1}[\mathrm{p}() \vee \neg \mathrm{p}()]$. Then:

$$
\mathrm{KTT}_{m} \vDash \overline{f_{n}} \text { if and only if } m \geq n \text {. }
$$

Proof: $\Leftarrow$ follows from Theorem 4.8 and Lemma $3.4 . \Rightarrow$ is by induction on $n$. Observe that

$$
\overline{f_{n}} \equiv \forall \mathrm{p}\left[\neg \operatorname{Typ}_{()^{x-1}}(\mathrm{p}) \vee\left(\mathrm{T}\left(\mathrm{App}_{0}(\mathrm{p})\right) \vee \neg \mathrm{T}\left(\mathrm{App}_{0}(\mathrm{p})\right)\right)\right] .
$$

- $n=1$. Let $g$ be any proposition of order 0 in RTT. Then $\operatorname{KTT}_{0} \vDash \operatorname{Typ}_{()^{\circ}}(g)$ but as $\mathrm{T}$ is completely undefined at level $0, \mathrm{KTT}_{0} \not \models \mathrm{T}\left(\operatorname{App}_{0}(g)\right) \vee \neg \mathrm{T}\left(\operatorname{App}_{0}(g)\right)$. Hence, $\mathrm{KTT}_{0} \not \models \overline{f_{1}}$.

- Assume the theorem has been proved for all $n^{\prime}<n$. Assume $m<n$ and $\operatorname{KTT}_{m} \vDash f_{n}$. By definition of $\models$, we have: $\operatorname{KTT}_{m} \vDash \mathrm{T}\left(\operatorname{App}_{0}\left(\left\langle\overline{f_{n-1}}\right\rangle\right)\right) \vee \neg \mathrm{T}\left(\operatorname{App}_{0}\left(\left\langle\overline{f_{n-1}}\right\rangle\right)\right)$, and for reasons of consistency: $\operatorname{KTT}_{m} \models \mathrm{T}\left(\operatorname{App}_{0}\left(\left\langle\overline{f_{n-1}}\right\rangle\right)\right)$, hence $\operatorname{KTT}_{m} \vDash \mathrm{T}\left(\overline{f_{n-1}}\right)$, so, by the definition of $\mathrm{T}$ : $\mathrm{KTT}_{m-1} \vDash \overline{f_{n-1}}$, which contradicts the induction hypothesis, as $m-1<n-1$.

There are, however, propositions $f$ of order $n$ in RTT for which $\mathrm{KTT}_{m} \models \bar{f}$ or $\mathrm{KTT}_{m} \vDash \overline{\neg f}$ can already be established for $m<n$.

Example 4.11 Consider a proposition $g \equiv g_{1} \vee g_{2}$ where $g_{1}$ is a true proposition of order $m$ and $g_{2}$ is any proposition of order $n$. As $g_{1}$ is true in RTT, we have $\mathrm{KTT}_{m} \vDash \overline{g_{1}}$, and therefore $\mathrm{KTT}_{m} \vDash \bar{g}$.

\section{$4 \mathrm{~b}$ The restrictiveness of Russell's theory}

We illustrate the different approaches of Russell and Kripke by an example given by Kripke himself

Example 4.12 Let $D, \mathcal{R}, L, S_{\alpha, i}$ and $\mathrm{KTT}_{\alpha}$ be as in Section 3 where $\mathcal{R}$ contains two monadic predicates $\mathrm{V}$ and $\mathrm{W}$ which are collections of (codes of) utterances of persons $\mathrm{V}$ and $\mathrm{W}$. Now define

$$
\begin{aligned}
& P \equiv \forall \mathbf{x}[\neg \mathbb{W}(\mathbf{x}) \vee \neg \mathbf{T}(\mathbf{x})] \\
& Q \equiv \forall \mathbf{x}[\neg \mathbb{V}(\mathbf{x}) \vee \neg \mathbf{T}(\mathbf{x})]
\end{aligned}
$$

(informally, $P$ denotes: All utterances of $\mathrm{W}$ are false, and $Q$ denotes: All utterances of $\mathrm{V}$ are false). Now distinguish two situations. In both situations, we want to know whether $P$ and $Q$ become true or false when passing through the hierarchy of languages $\mathrm{KTT}_{0}, \mathrm{KTT}_{1}, \ldots$ Or, more formally, whether there is $\alpha$ such that $\langle\mathrm{V}\rangle$ and $\langle\mathrm{W}\rangle$ belong to $S_{\alpha, 1} \cup S_{\alpha, 2}$.

1. $\mathrm{V}=\{\langle P\rangle\}$ and $\mathrm{W}=\{\langle Q\rangle\}$ (notice that $\mathrm{v}$ and $\mathrm{w}$ are just subsets of $D)$.

In this case, $P$ is logically equivalent to $\neg \mathrm{T}(\langle Q\rangle)$ and $Q$ is logically equivalent to $\neg \mathrm{T}(\langle P\rangle)$. As a consequence we have: if $\langle Q\rangle \in S_{\alpha, i}$ then $\langle P\rangle \in S_{\beta, 3-i}$ for some $\beta<\alpha$, and if $\langle P\rangle \in S_{\alpha, i}$ then $\langle Q\rangle \in S_{\beta, 3-i}$ for some $\beta<\alpha$. Hence $\langle P\rangle,\langle Q\rangle \notin S_{\alpha_{1}}$, for all $\alpha, i$, so neither the truth of $P$ nor the truth of $Q$ will ever be established.

2. In the situation above, the only utterance of $\mathrm{V}$ was that anything said by $\mathrm{W}$ is false, and vice versa. In that case, it is also intuitively clear that it is impossible to say anything about the truth of $P$ or $Q$. Now we change the situation. We assume that $\mathcal{R}$ also contains a third monadic predicate $\mathrm{R}$, and that $\mathrm{d}$ is an element of $\mathrm{R}$. We redefine $\mathrm{W}$ :

$$
W \stackrel{\text { def }}{=}\{\langle Q\rangle,\langle\mathrm{R}(\mathrm{d})\rangle\} \text {. }
$$

This has drastical consequences. As $\mathrm{KTT}_{0} \vDash \mathrm{R}(\mathrm{d}),\langle\mathrm{R}(\mathrm{d})\rangle \in S_{1, \mathrm{1}}$, so $\mathrm{KT}_{1} \vDash \mathrm{T}(\langle\mathrm{R}(\mathrm{d})\rangle)$, hence $\mathrm{KTT}_{1} \vDash \neg P$. Therefore, $\langle P\rangle \in S_{2,2}$, so KTт, $\vDash \neg \mathrm{T}(\langle\mathrm{P}\rangle)$, hence:

$$
\begin{aligned}
& \mathrm{KTT}_{2} \vDash \neg P \\
& \mathrm{KTT}_{2} \vDash Q
\end{aligned}
$$

The fact that $W$ utters a true sentence makes it possible to conclude at level 1 that $P$ is false, irrespective of the fact that $W$ has also uttered another sentence $Q$, of which we can't establish the truth at level 1. The falsehood of $P$ makes it possible to decide about $Q$ at the next level, so the falsehood of $P$ and the truth of $Q$ could have been established at level 2. 
In Russell's terminology it wouldn't be possible to write expressions like $P$ and $Q$ at all: They are excluded beforehand, as $P$ involves $Q$, therefore has to be of higher order than $Q$, and $Q$ involves $P$, therefore has to be of higher order than $P$.

This indicates an important difference between RTT and KTT: Kripke allows much more expressions to be written down. In some situations these expressions will never obtain any truth-value (like $P$ and $Q$ in the first example), but in other situations (so: with other definitions of the primitive predicates) the same expressions will get a truth-value. Kripke concludes: "it would be fruitless to look for an intrinsic criterion that will enable us to sieve out - as meaningless, or ill-formed those sentences which lead to paradox".

Example 4.13 Another, more formal, example of a proposition $f$ in KTT for which there is no $g \in \mathcal{F}$ with $\bar{g} \equiv f$ is the proposition $f \stackrel{\text { def }}{=} \forall \mathrm{x}[\mathrm{T}(\mathbf{x}) \vee \neg \mathrm{T}(\mathbf{x})]$ :

Assume, for the sake of the argument, that $\bar{g} \equiv f$. Let $m$ be the order of $g$. Then $\mathrm{KTT}_{m} \vDash f$ or $\mathrm{KTT}_{m} \vDash \neg f$. This implies $\mathrm{KTT}_{m} \vDash \mathrm{T}\left(f_{m}\right) \vee \neg \mathrm{T}\left(f_{m}\right)$, where $f_{m}$ is as in Theorem 4.10. By definition of T this means KTT $\mathrm{KT}_{m-1} \vDash f_{m}$ or $\mathrm{KTT}_{m-1} \vDash \neg f_{m}$, both contradicting Theorem 4.10.

\section{Orders and Types}

RTT is based on a double hierarchy: One of types and one of orders. This double hierarchy is too restrictive. It is possible to develop Logic and Mathematics within RTT, but for instance the proof of the Supremum Theorem, which is fundamental in real analysis, cannot be given. The origin of the problem is the use of the so-called predicative and impredicative propositional functions.

Definition 5.1 Let $f \in \mathcal{F}$ be typable in RTT. Assume $f$ has free variables $x_{1}, \ldots, x_{n}$ of orders $m_{1}, \ldots, m_{n}$ respectively. $f$ is called predicative if its order is equal to $\max \left(m_{1}, \ldots, m_{n}\right)+1$; if its order is greater then $f$ is called impredicative.

As the impredicative propositional functions cause problems, the "Axiom of Reducibility" is proposed in "Principia Mathematica" (1910-1912). This axiom is as follows:

For each $f \in \mathcal{F}$ there is a predicative $g \in \mathcal{F}$ that is logically equivalent to $f$

This axiom has been controversial from the moment it was introduced. Russell himself admits that "it has a purely pragmatic justification: it leads to the desired results, and to no others. But clearly it is not the sort of axiom with which we can rest content." Though serious efforts have been made to develop Mathematics within RTT (for instance by Weyl [14]), this has not become the usual practice. In 1925, Ramsey [10] shows that, by making distinction between language and meta-language, the orders can be removed from the system without re-introducing any known paradox. Hilbert and Ackermann [6] present a similar idea. With this remark the type-theoretic fundaments for the Simple Theory of Types STT, introduced by Church [1] in 1940, were laid, and orders have remained out of the important modern type systems up till now.

It is therefore interesting to notice the relation between orders in RTT and levels of truth in KTT, as formulated in Theorem 4.8. It shows that Kripke's system can be regarded as a system based on RTT, of which not the orders, but the types have been removed. In this way, KTT can be seen as a system that is dual to STT.

KTT, however, has a more subtle approach than many type theories as it does not exclude any, possibly "paradoxical", expression from the syntax, which is the usual type-theoretic approach. If an expression is paradoxical, it will not get a truth value at any level $\alpha$ of the hierarchy of Truths. Whether an expression is paradoxical or not does not only depend on its syntactic structure, but also on the domain $D$ (see Example 4.12). So paradoxes are only excluded at the level of semantics.

The discussion above shows that the orders of RTT are not to be blamed for the restrictiveness of RTT. KTT is a system which contains orders but has only few restrictions towards self-application. It is the combination of orders and types that makes RTT restrictive. 


\section{Conclusion}

\section{6a Results}

We presented a formalisation of Russell's Ramified Theory of 'Types RTT which is faithful to both Russell's original informal presentation and the present formulations of type theories.

We used this formalisation to compare RTT with Kripke's Theory of Truth KTT. We established the relation between Russell's hierarchy of orders and Kripke's hierarchy of truth-levels. In particular we showed that

1. A proposition of RT'T of order $n$ is true if and only if it is true at level $n$ in Kripke's Truth Hierarchy (Theorem 4.8).

2. The truth of some propositions of order $n$ of RTT cannot be established in KTT at a level of truth hierarchy smaller than $n$ (Theorem 4.10). Yet for some other propositions, it can be established at an earlier level (Example 4.11).

We also saw that Russell's theory has many restrictions. On the one hand, all propositional functions of RTT can be coded in Kripke's Truth Theory; on the other hand there are formulas of Kripke's theory that cannot be expressed in RTT, respecting both hierarchies.

We conclude, as so often has been concluded in Logic, in Mathematics and in Natural Language, that Russell's Theory of Types is too restrictive. However, the usual objections against RTT in Logic and Mathematics is the use of orders. After Ramsey [10] and Hilbert and Ackerman [6] had given motivations for leaving out these orders, they have hardly been used anywhere in logic or mathematics (though Weyl [14] has tried to give a build-up of mathematics within RTT).

Here the situation is completely different. Orders in RTT and truth-levels in KTT go hand in hand; on the other hand the types do not appear any more in KTT. This establishes KTT as the dual to STT (Church's Simple Type Theory) which removes the orders from RTT.

\section{6b Future work}

Kripke's theory has a tranfinite hierarchy of orders whereas Russell did not investigate such transfinity. It would be interesting hence to see how far one can build types in Russell's theory and what properties would hold at such level.

We concluded that some order- $n$-properties of RTT get their truth-value only at level $n$ of KTT whilst others get it already at an earlier level. This divides propositions into two classes and an accurate description of these classes may be interesting.

As to the question of Kripke being more liberal in that any sentence can be expressed but its truth value may not be calculated (think of the paradoxical sentences), one may compare this approach to the implicit typing of Curry's Type Theory CTT $[2,3]$ where self-referential sentences may be expressed but are not typable. Hence, even though we said that KTT is the dual of STT, it may be the twin-brother of CTT where only truth or falsehood of typable terms can be determined. We are currently investigating this issue.

\section{References}

[1] A. Church. A formulation of the simple theory of types. The Journal of Symbolic Logic, 5:56-68, 1940.

[2] H.B. Curry and R. Feys. Combinatory Logic, volume I of Studies in Logic and the Foundations of Mathematics. North-Holland, Amsterdam, 1958.

[3] H.B. Curry, J.R. Hindley, and J.P. Seldin. Combinatory Logic, volume II of Studies in Logic and the Foundations of Mathematics. North-Holland, Amsterdam, 1972. 
[4] G. Frege. Begriffschrift, eine der arithmetischen nachgebildete Formelsprache des reinen Denkens. Nebert, Halle, 1879. Also in [5].

[5] J. van Heijenoort, editor. From Frege to Gödel: A Source Book in Mathematical Logic, 1879 1931. Harvard University Press, Cambridge, Massachusetts, 1967.

[6] D. Hilbert and W. Ackermann. Grundzüge der Theoretischen Logik. Die Grundlehren der Mathematischen Wissenschaften in Einzeldarstellungen, Band XXVII. Springer Verlag, Berlin, first edition, 1928.

[7] S. Kripke. Outline of a theory of truth. Journal of Philosophy, 72:690-716, 1975.

[8] T.D.L. Laan. A formalization of the Ramified Type Theory. Technical Report 33, TUE Computing Science Reports, Eindhoven University of Technology, 1994.

[9] R. Montague. The proper treatment of quantification in ordinary English. In J. Hintikka, J.M.E. Moravcsik, and P. Suppes, editors, Approaches to Natural Language. Dordrecht, 1973.

[10] F.P. Ramsey. The foundations of mathematics. Proceedings of the London Mathematical Society, pages $338-384,1925$.

[11] B. Russell. The Principles of Mathematics. Allen \& Unwin, London, 1903.

[12] B. Russell. Mathematical logic as based on the theory of types. American Journal of Mathematics, 30, 1908. Also in [5].

[13] A. Tarski. Der Wahrheitsbegriff in den formalisierten Sprachen. Studia Philosophica, 1:261405, 1936. German translation by L. Blauwstein from the Polish original (1933) with a postscript added.

[14] H. Weyl. Das Kontinuum. Veit, Leipzig, 1918. German; also in: Das Kontinuum und andere Monographien, Chelsea Pub.Comp., New York, 1960.

[15] A.N. Whitehead and B. Russell. Principia Mathematica. Cambridge University Press, $1910^{1}$, $1927^{2}$. (All references in this paper are to the first volume). 


\section{Computing Science Reports}

In this series appeared:

\begin{tabular}{|c|c|}
\hline 93/01 & R. van Geldrop \\
\hline $93 / 02$ & T. Verhoeff \\
\hline $93 / 03$ & T. Verhoeff \\
\hline $93 / 04$ & $\begin{array}{l}\text { E.H.L. Aarts } \\
\text { J.H.M. Korst } \\
\text { P.J. Zwietering }\end{array}$ \\
\hline 93/05 & $\begin{array}{l}\text { J.C.M. Baeten } \\
\text { C. Verhoef }\end{array}$ \\
\hline $93 / 06$ & J.P. Velıkamp \\
\hline $93 / 07$ & P.D. Moerland \\
\hline $93 / 08$ & J. Verhoosel \\
\hline 93109 & K.M. van Hee \\
\hline $93 / 10$ & K.M. van Hee \\
\hline $93 / 11$ & K.M. van Hee \\
\hline $93 / 12$ & K.M. van Hee \\
\hline $93 / 13$ & K.M. van Hee \\
\hline $93 / 14$ & $\begin{array}{l}\text { J.C.M. Baeten } \\
\text { J.A. Bergstra }\end{array}$ \\
\hline $93 / 15$ & $\begin{array}{l}\text { J.C.M. Baeten } \\
\text { J.A. Bergstra } \\
\text { R.N. Bol }\end{array}$ \\
\hline $93 / 16$ & $\begin{array}{l}\text { H. Schepers } \\
\text { J. Hooman }\end{array}$ \\
\hline $93 / 17$ & $\begin{array}{l}\text { D. Alstein } \\
\text { P. van der Stok }\end{array}$ \\
\hline $93 / 18$ & C. Verhoef \\
\hline $93 / 19$ & G-J. Houben \\
\hline $93 / 20$ & F.S. de Boer \\
\hline $93 / 21$ & $\begin{array}{l}\text { M. Codish } \\
\text { D. Dams } \\
\text { G. File } \\
\text { M. Bruynooghe }\end{array}$ \\
\hline $93 / 22$ & E. Poll \\
\hline $93 / 23$ & E. de Kogel \\
\hline $93 / 24$ & E. Poll and Paula Severi \\
\hline $93 / 25$ & H. Schepers and R. Gerth \\
\hline $93 / 26$ & W.M.P. van der Aalst \\
\hline $93 / 27$ & T. Kloks and D. Kratsch \\
\hline $93 / 28$ & $\begin{array}{l}\text { F. Kamareddine and } \\
\text { R. Nederpelt }\end{array}$ \\
\hline $93 / 29$ & R. Post and P. De Bra \\
\hline $93 / 30$ & $\begin{array}{l}\text { J. Deogun } \\
\text { T. Kloks } \\
\text { D. Kratsch } \\
\text { H. Müller }\end{array}$ \\
\hline
\end{tabular}

\section{Department of Mathematics and Computing Science Eindhoven University of Technology}

Deriving the Aho-Corasick algorithms: a case study into the synergy of programming methods, p. 36.

A continuous version of the Prisoner's Dilemma, p. 17

Quicksort for linked lists, p. 8.

Deterministic and randomized local search, p. 78.

A congruence theorem for structured operational semantics with predicates, p. 18.

On the unavoidability of metastable behaviour, p. 29

Exercises in Multiprogramming, p. 97

A Formal Deterministic Scheduling Model for Hard Real-Time Execurions in DEDOS, p. 32.

Systems Engineering: a Formal Approach

Pant I: System Concepts, p. 72.

Systems Engineering: a Formal Approach Part II: Frameworks, p. 44.

Systems Engineering: a Formal Approach Pat III: Modeling Methods, p. 101

Systerns Engineering: a Formal Approach Pant IV: Analysis Methods, p. 63.

Systems Engineering: a Formal Approach Pan V: Specification Language, p. 89.

On Sequential Composition, Action Prefixes and Process Prefix, p. 21.

A Real-Time Process Logic, p. 31.

A Trace-Based Compositional Proof Theory for Fault Tolerant Distributed Systems, p. 27

Hard Real-Time Reliable Multicast in the DEDOS system, p. 19.

A congruence theorem for structured operational semantics with predicates and negative premises, p. 22.

The Design of an Online Help Facility for ExSpect, p.21.

A Process Algebra of Concurrent Constraint Programming, p. 15.

Freeness Analysis for Logic Programs - And Correctness, p. 24

A Typechecker for Bijective Pure Type Systems, p. 28.

Relational Algebra and Equational Proofs, p. 23.

Pure Type Systems with Definitions, p. 38.

A Compositional Proof Theory for Fault Tolerant Real-Time Distributed Systems, p. 31.

Multi-dimensional Petri nets, p. 25.

Finding all minimal separators of a graph, p. 11 .

A Sernantics for a fine $\lambda$-calculus with de Bruijn indices, p. 49.

GOLD, a Graph Oriented Language for Databases, p. 42.

On Vertex Ranking for Permutation and Other Graphs, p. 11. 


\begin{tabular}{|c|c|}
\hline $93 / 31$ & W. Körver \\
\hline $93 / 32$ & $\begin{array}{l}\text { H. ten Eikelder and } \\
\text { H. van Geld rop }\end{array}$ \\
\hline $93 / 33$ & L. Loyens and J. Moonen \\
\hline $93 / 34$ & $\begin{array}{l}\text { J.C.M. Baeten and } \\
\text { J.A. Bergstra }\end{array}$ \\
\hline $93 / 35$ & $\begin{array}{l}\text { W. Ferrer and } \\
\text { P. Severi }\end{array}$ \\
\hline $93 / 36$ & $\begin{array}{l}\text { J.C.M. Baeten and } \\
\text { J.A. Bergstra }\end{array}$ \\
\hline $93 / 37$ & $\begin{array}{l}\text { J. Brunekreef } \\
\text { J-P. Katcen } \\
\text { R. Koymans } \\
\text { S. Mauw }\end{array}$ \\
\hline $93 / 38$ & C. Verhoef \\
\hline $93 / 39$ & $\begin{array}{l}\text { W.P.M. Nuijten } \\
\text { E.H.L. Aarts } \\
\text { D.A.A. van Erp Taalman Kip } \\
\text { K.M. van Hee }\end{array}$ \\
\hline $93 / 40$ & $\begin{array}{l}\text { P.D.V. van der Stok } \\
\text { M.M.M.PJ. Claessen } \\
\text { D. Alstein }\end{array}$ \\
\hline $93 / 41$ & A. Bijlsma \\
\hline $93 / 42$ & P.M.P. Rambags \\
\hline $93 / 43$ & B.W. Watson \\
\hline $93 / 44$ & B.W. Watson \\
\hline $93 / 45$ & $\begin{array}{l}\text { E.J. Luit } \\
\text { J.M.M. Martin }\end{array}$ \\
\hline $93 / 46$ & $\begin{array}{l}\text { T. Kloks } \\
\text { D. Kratsch } \\
\text { J. Spinrad }\end{array}$ \\
\hline $93 / 47$ & $\begin{array}{l}\text { W. v.d. Aalst } \\
\text { P. De Bra } \\
\text { G.J. Houben } \\
\text { Y. Komatzky }\end{array}$ \\
\hline $93 / 48$ & R. Gerth \\
\hline $94 / 01$ & $\begin{array}{l}\text { P. America } \\
\text { M. van der Kammen } \\
\text { R.P. Nederpelt } \\
\text { O.S. van Roosmalen } \\
\text { H.C.M. de Swart }\end{array}$ \\
\hline $94 / 02$ & $\begin{array}{l}\text { F. Kamareddine } \\
\text { R.P. Nederpelt }\end{array}$ \\
\hline $94 / 03$ & $\begin{array}{l}\text { L.B. Hartman } \\
\text { K.M. van Hee }\end{array}$ \\
\hline $94 / 04$ & $\begin{array}{l}\text { J.C.M. Baeten } \\
\text { J.A. Bergstra }\end{array}$ \\
\hline $94 / 05$ & $\begin{array}{l}\text { P. Zhou } \\
\text { J. Hooman }\end{array}$ \\
\hline $94 / 06$ & $\begin{array}{l}\text { T. Basten } \\
\text { T. Kunz } \\
\text { J. Black } \\
\text { M. Coffin } \\
\text { D. Taylor }\end{array}$ \\
\hline $94 / 07$ & $\begin{array}{l}\text { K.R. Apt } \\
\text { R. Bol }\end{array}$ \\
\hline $94 / 08$ & O.S. van Roosmalen \\
\hline $94 / 09$ & $\begin{array}{l}\text { J.C.M. Baeten } \\
\text { J.A. Bergstra }\end{array}$ \\
\hline
\end{tabular}

Derivation of delay insensitive and speed independent CMOS circuits, using directed commands and production rule sets, p. 40.

On the Correctness of some Algorithms to generate Finite Automata for Regular Expressions, p. 17.

ILIAS, a sequential language for parallel matrix computations, p. 20.

Real Time Process Algebra with Infinitesimals, p.39.

Abstract Recuction and Topology, p. 28.

Non Interleaving Process Algebra, p. 17.

Design and Analysis of

Dynamic Leader Election Protocols

in Broadcast Networks, p. 73.

A general conservative extension theorem in process algebra, p. 17.

Job Shop Schatuling by Constraint Satisfaction, p. 22.

A Hierarchical Membership Protocol for Synchronous Distributed Systems, p. 43.

Temporal operators viewed as predicate transformers, p. 11.

Automatic Verification of Regular Protocols in P/T Nets, p. 23.

A taxomomy of finite automata construction algorithms, p. 87.

A taxonomy of finite automata minimization algorithms, p. 23.

A precise clock synchronization protocol,p.

Treewidth and Patwidth of Cocomparability graphs of Bounded Dimension, p. 14.

Browsing Semantics in the "Tower" Model, p. 19.

Verifying Sequentially Consistent Memory using Interface Refinement, p. 20.

The object-oriented paradigm, p. 28.

Canonical typing and II-conversion, p. 51.

Application of Marcov Decision Processe to Search Problems, p. 21.

Graph Isomorphism Models for Non Interleaving Process Algebra, p. 18.

Formal Specification and Compositional Verification of an Atomic Broadcast Protocol, p. 22.

Time and the Order of Abstract Events in Distributed Computations, p. 29.

Logic Programming and Negation: A Survey, p. 62.

A Hierarchical Diagrammatic Representation of Class Structure, p. 22.

Process Algebra with Partial Choice, p. 16. 


\begin{tabular}{|c|c|}
\hline $94 / 10$ & T. verhoeff \\
\hline $94 / 11$ & $\begin{array}{l}\text { J. Peleska } \\
\text { C. Huizing } \\
\text { C. Petersohn }\end{array}$ \\
\hline $94 / 12$ & $\begin{array}{l}\text { T. Kloks } \\
\text { D. Kratsch } \\
\text { H. Muiller }\end{array}$ \\
\hline $94 / 13$ & R. Seljée \\
\hline $94 / 14$ & W. Peremans \\
\hline $94 / 15$ & $\begin{array}{l}\text { R.J.M. Vaessens } \\
\text { E.H.L. Aarts } \\
\text { J.K. Lenstra }\end{array}$ \\
\hline $94 / 16$ & $\begin{array}{l}\text { R.C. Backhouse } \\
\text { H. Doombos }\end{array}$ \\
\hline $94 / 17$ & $\begin{array}{l}\text { S. Mauw } \\
\text { M.A. Reniers }\end{array}$ \\
\hline $94 / 18$ & $\begin{array}{l}\text { F. Karnareddine } \\
\text { R. Nederpelt }\end{array}$ \\
\hline $94 / 19$ & B.W. Watson \\
\hline $94 / 20$ & $\begin{array}{l}\text { R. Bloo } \\
\text { F. Kamareddine } \\
\text { R. Nederpelt }\end{array}$ \\
\hline $94 / 21$ & B.W. Watson \\
\hline $94 / 22$ & B.W. Watson \\
\hline $94 / 23$ & S. Mauw and M.A. Reniers \\
\hline $94 / 24$ & $\begin{array}{l}\text { D. Dams } \\
\text { O. Grumberg } \\
\text { R. Gerth }\end{array}$ \\
\hline $94 / 25$ & T. Kloks \\
\hline $94 / 26$ & R.R. Hoogerwoord \\
\hline $94 / 27$ & S. Mauw and H. Mulder \\
\hline $94 / 28$ & $\begin{array}{l}\text { C.W.A.M. van Overveld } \\
\text { M. Verhoeven }\end{array}$ \\
\hline $94 / 29$ & J. Hooman \\
\hline $94 / 30$ & $\begin{array}{l}\text { J.C.M. Baeten } \\
\text { J.A. Bergstra } \\
\text { Gh. Ştefanescu }\end{array}$ \\
\hline $94 / 31$ & $\begin{array}{l}\text { B.W. Watson } \\
\text { R.E. Watson }\end{array}$ \\
\hline $94 / 32$ & J.J. Vereijken \\
\hline $94 / 33$ & T. Laan \\
\hline $94 / 34$ & $\begin{array}{l}\text { R. Bloo } \\
\text { F. Kamareddine } \\
\text { R. Nederpelt }\end{array}$ \\
\hline $94 / 35$ & $\begin{array}{l}\text { J.C.M. Baeten } \\
\text { S. Mauw }\end{array}$ \\
\hline $94 / 36$ & $\begin{array}{l}\text { F. Kamareddine } \\
\text { R. Nederpelt }\end{array}$ \\
\hline $94 / 37$ & $\begin{array}{l}\text { T. Basten } \\
\text { R. Bol } \\
\text { M. Voorhoeve }\end{array}$ \\
\hline $94 / 38$ & $\begin{array}{l}\text { A. Bijlsma } \\
\text { C.S. Scholten }\end{array}$ \\
\hline
\end{tabular}

The testing Paradigm Applied to Network Structure. p. 31 .

A Comparison of Ward \& Mellor's Transformation

Schema with State- \& Activitycharts, p. 30.

Dominoes, p. 14.

A New Method for Integrity Constraim checking in Deductive Databases, p. 34.

Ups and Downs of Type Theory, p. 9.

Job Shop Scheduling by Local Search, p. 21.

Mathematical Induction Made Calculational, p. 36.

An Algebraic Semantics of Basic Message

Sequence Charts, p. 9.

Refining Reduction in the Lambda Calculus, p. 15.

The performance of single-keyword and multiple-keyword pattem matching algorithms, p. 46.

Beyond $\beta$-Reduction in Church's $\lambda \rightarrow$, p. 22.

An introduction to the Fire engine: A C++ toolkit for Finite automata and Regular Expressions.

The design and implementation of the FIRE engine:

A C++ toolkit for Finite automata and regular Expressions.

An algebraic semantics of Message Sequence Charts, p. 43.

Abstract Interpretation of Reactive Systems:

Abstractions Preserving $\forall C T L *, \exists C T L^{*}$ and $C T L *$ p. 28.

$K_{1,3}$-free and $W_{4}$-free graphs, p. 10 .

On the foundations of functional programming: a programmer's point of view, $p$. 54.

Regularity of BPA-Systems is Decidable, p. 14.

Stars or Stripes: a comparative study of finite and transfinite techniques for surface modelling, p. 20.

Correctness of Real Time Systems by Construction, p. 22.

Process Algebra with Feedback, p. 22.

A Boyer-Moore type algorithm for regular expression pattem matching, p. 22.

Fischer's Protocol in Timed Process Algebra, p. 38.

A formalization of the Ramified Type Theory, p.40.

The Barendregt Cube with Definitions and Generalised

Reduction, p. 37 .

Delayed choice: an operator for joining Message

Sequence Charts, p. 15.

Canonical typing and $\Pi$-conversion in the Barendregt

Cube, p. 19.

Simulating and Analyzing Railway Interlockings in

ExSpect, p. 30.

Point-free substitution, p. 10. 


\begin{tabular}{|c|c|c|}
\hline $94 / 39$ & $\begin{array}{l}\text { A. Blokhuis } \\
\text { T. Kloks }\end{array}$ & \\
\hline $94 / 40$ & D. Alstein & \\
\hline $94 / 41$ & $\begin{array}{l}\text { T. Kloks } \\
\text { D. Kratsch }\end{array}$ & \\
\hline $94 / 42$ & $\begin{array}{l}\text { J. Engelfriet } \\
\text { J.J. Vereijken }\end{array}$ & \\
\hline $94 / 43$ & $\begin{array}{l}\text { R.C. Backhouse } \\
\text { M. Bijsterveld }\end{array}$ & \\
\hline $94 / 44$ & $\begin{array}{l}\text { E. Brinksma } \\
\text { R. Gerth } \\
\text { W. Janssen } \\
\text { S. Katz } \\
\text { M. Poel } \\
\text { C. Rump }\end{array}$ & $\begin{array}{l}\text { J. Davies } \\
\text { S. Graf } \\
\text { B. Jonsson } \\
\text { G. Lowe } \\
\text { A. Pnueli } \\
\text { J. Zwiers }\end{array}$ \\
\hline $94 / 45$ & G.J. Houben & \\
\hline $94 / 46$ & $\begin{array}{l}\text { R. Bloo } \\
\text { F. Kamareddine } \\
\text { R. Nederpelt }\end{array}$ & \\
\hline $94 / 47$ & $\begin{array}{l}\text { R. Bloo } \\
\text { F. Kamareddine } \\
\text { R. Nederpelt }\end{array}$ & \\
\hline $94 / 48$ & $\begin{array}{l}\text { Mathematics of Prog } \\
\text { Construction Group }\end{array}$ & ram \\
\hline $94 / 49$ & $\begin{array}{l}\text { J.C.M. Baeten } \\
\text { J.A. Bergstra }\end{array}$ & \\
\hline $94 / 50$ & H. Geuvers & \\
\hline $94 / 51$ & $\begin{array}{l}\text { T. Kloks } \\
\text { D. Kratsch } \\
\text { H. Müller }\end{array}$ & \\
\hline $94 / 52$ & $\begin{array}{l}\text { W. Penczek } \\
\text { R. Kuiper }\end{array}$ & \\
\hline $94 / 53$ & $\begin{array}{l}\text { R. Gerth } \\
\text { R. Kuiper } \\
\text { D. Peled } \\
\text { W. Penczek }\end{array}$ & \\
\hline $95 / 01$ & J.J. Lukkien & \\
\hline $95 / 02$ & $\begin{array}{l}\text { M. Bezem } \\
\text { R. Bol } \\
\text { J.F. Groote }\end{array}$ & \\
\hline $95 / 03$ & $\begin{array}{l}\text { J.C.M. Baeten } \\
\text { C. Vemoef }\end{array}$ & \\
\hline $95 / 04$ & J. Hidders & \\
\hline $95 / 05$ & P. Severi & \\
\hline $95 / 06$ & $\begin{array}{l}\text { T.W.M. Vossen } \\
\text { M.G.A. Verhoeven } \\
\text { H.M.M. ten Eikelder } \\
\text { E.H.L. Aarts }\end{array}$ & \\
\hline $95 / 07$ & $\begin{array}{l}\text { G.A.M. de Bruyn } \\
\text { OS. van Roosmalen }\end{array}$ & \\
\hline $95 / 08$ & R. Bloo & \\
\hline $95 / 09$ & $\begin{array}{l}\text { J.C.M. Baeten } \\
\text { J.A. Bergstra }\end{array}$ & \\
\hline $95 / 10$ & $\begin{array}{l}\text { R.C. Backhouse } \\
\text { R. Verhoeven } \\
\text { O. Weber }\end{array}$ & \\
\hline
\end{tabular}

On the equivalence covering number of splitgraphs, p. 4.

Distributed Consensus and Hard Real-Time Systems, p. 34.

Computing a perfect edge without vertex elimination ordering of a chordal bipartite graph, p. 6.

Concatenation of Graphs, p. 7.

Category Theory as Coherently Constructive Latrice Theory: An Illustration, p. 35.

Verifying Sequentially Consistent Memory, p. 160

Tutorial voor de ExSpect-bibliotheek voor "Administratieve Logistiek", p. 43.

The $\lambda$-cube with classes of terms modulo conversion, p. 16.

On II-conversion in Type Theory, p. 12.

Fixed-Point Calculus, p. 11.

Process Algebra with Propositional Signals, p. 25.

A short and flexible proof of Strong Normalazation for the Calculus of Constructions, p. 27.

Listing simplicial vertices and recognizing diamond-free graphs, p. 4.

Traces and Logic, p. 81

A Partial Order Approach to Branching Time Logic Model Checking, p. 20.

The Construction of a small CommunicationLibrary, p.16.

Formalizing Process Algebraic Verifications in the Calculus of Constructions, p.49.

Concrete process algebra, p. 134.

An Isotopic Invariant for Planar Drawings of Connected Planar Graphs, p. 9. A Type Inference Algorithm for Pure Type Systems, p.20.

A Quantitative Analysis of Iterated Local Search, p.23.

Drawing Execution Graphs by Parsing, p. 10.

Preservation of Strong Normalisation for Explicit Substitution, p. 12.

Discrete Time Process Algebra, p. 20

Math/pad: A System for On-Line Prepararation of Mathematical Documents, p. 15 
$95 / 14$ A. Ponse, C. Verhoef, S.F.M. Vlijmen (eds.)

$95 / 15$ P. Niebert and W. Penczek

95/16

$95 / 17$
D. Dams, O. Grumberg, R. Gerth

S. Mauw and E.A. van der Meulen
Deductive Database Systems and integrity constraint checking, p. 36.

Empty Interworkings and Refinement Semantics of Interworkings Revised, p. 19.

A taxonomy of sublinear multiple keyword pattern matching slgorithms, p. 26. De proceedings: ACP'95, p.

On the Connection of Partial Order Logics and Partial Order Reduction Methods, p. 12.

Abstract Interpretation of Reactive Systems: Preservation of CTL*, p. 27.

Specification of tools for Message Sequence Charts, p. 36. 
. 